\title{
Early mannitol administration improves clinical outcomes of pediatric patients with brain edema
}

\author{
Putu A. Sekarningrum, Dyah K. Wati, IGN Made Suwarba, I Nyoman B. Hartawan, Dewi S. Mahalini, IB \\ Gede Suparyatha
}

Department of Pediatric, Faculty of Medicine, University of Udayana/Sanglah Hospital, Bali, Indonesia

\section{ABSTRACT}

Background: Mannitol 20\% is used to treat patients with decreased consciousness and as the first line of treatment to reduce intracranial pressure (ICP). However, its application in pediatric patients is still based on minimal evidence. This study was performed to determine the predictive factors of clinical outcomes in pediatric patients with brain edema in the pediatric intensive care unit (PICU).

Methods: This prospective cohort study was conducted in the PICU, Sanglah Hospital Denpasar, Bali, Indonesia. The subjects were chosen by consecutive sampling from July 2016 to July 2017. The primary outcome variable was the patient's clinical outcome. A chi-square test was used to evaluate the association between the timing of mannitol administration and the patient's clinical outcome. Multivariate analysis was performed on all variables with $\mathrm{p} \leq 0.25$.

Results: Forty-one patients were included in the study, 65\% of them were male, $65 \%$ had good nutritional status, $90 \%$ had nontraumatic brain injury, and $73 \%$ had confirmed intracranial infection. The risk of sequelae or death for patients in a coma was 1.8 times greater than that of non-comatose patients ( $\mathrm{p}=0.018$; CI 95\% 1.119-3.047). Based on the timing of mannitol administration from the onset of decreased consciousness, the risk of sequelae or death in patients who received mannitol after 24 hours was 2.1 times higher than that in patients who received mannitol within 24 hours ( $p=0.006$; CI 95\% 1.167-3.779). Based on multivariate analysis, only two variables were associated with the patient's clinical outcome: pediatric Glasgow coma scale (PGCS) $\leq 3$ ( $p=0.03$ ) and timing of mannitol administration $>24$ hours $(\mathrm{p}=0.01)$.

Conclusion: Early administration ( $<24$ hours) of mannitol and high PGCS are related to favorable outcomes in patients with brain edema in the PICU.

Keywords: brain edema, clinical outcome, intracranial pressure, mannitol

pISSN: 0853-1773 • eISSN: 2252-8083 • https://doi.org/10.13181/mji.v27i4.2377 • Med J Indones. 2018;27:244-9

- Received 28 Oct $2017 \cdot$ Accepted 29 Oct 2018

Corresponding author: Dyah K. Wati

dyahpediatric@yahoo.com

Copyright @ 2018 Authors. This is an open access article distributed under the terms of the Creative Commons Attribution-NonCommercial 4.0 International License (http://creativecommons.org/licenses/by-nc/4.0/), which permits unrestricted non-commercial use, distribution, and reproduction in any medium, provided the original author and source are properly cited. 
In cases of both traumatic and nontraumatic brain injury, increased intracranial pressure is a recognizable feature and a major determinant of better outcomes. The treatment aim is to reduce intracranial pressure (ICP), therefore optimizing cerebral perfusion and thus the oxygen supply to the brain. ${ }^{1}$ The methods employed to reduce ICP include postural changes, drainage of cerebrospinal fluid, operative decompression, and osmotherapy. ${ }^{1,2}$

Mannitol, urea, sorbitol, glycerol, and hypertonic saline are several osmotic agents that act to reduce ICP by creating an osmotic gradient, and they have additional beneficial effects. Mannitol is the most frequently used., ${ }^{3,4}$ Mannitol can decrease brain volume by reducing the overall water content and vasoconstriction of the vascular bed in the brain. It also functions to improve cerebral perfusion by decreasing cerebral viscosity and to suppress the effects of free radicals and nitric oxide. ${ }^{5,6}$

Mannitol is used as the first line of treatment in patients with poor cerebral blood flow because it can increase the cerebral perfusion pressure and cerebral blood flow velocities, whereas hypertonic saline is considered in patients with hypovolemia or hyponatremia. ${ }^{1,3,4}$ Elevated intracranial pressure is multifactorial in cause and has an incidence of $63 \%$. Inadequate treatment will result in sequelae, ending with death. ${ }^{7}$ There are several methods of reducing intracranial pressure; the most widely used is administration of mannitol $20 \%$. However, application of such procedures to pediatric patients is still based on minimal research evidence from children with increased intracranial pressure. Guidelines for the treatment of children with non-traumatic brain injury are virtually non-existent. This study was performed to determine the predictive factors of clinical outcome in pediatric patients with brain edema in the pediatric intensive care unit (PICU).

\section{METHODS}

This prospective cohort study was conducted in the PICU, Sanglah Hospital, Denpasar. The subjects were chosen by consecutive sampling from July 2016 to July 2017 . The sample size was calculated using an analytical unpaired categorical formula. The mortality rate in patients with brain edema was $24 \%$, with a significance level of 0.05 , a power of $80 \%$, and an assumed relative risk of 3. ${ }^{7}$ This is the first study on the outcome of mannitol administration in children; therefore, we used the mortality rate reported by Mohanty et al, ${ }^{7}$ but the determination of relative risk was based on researcher assumptions, and the general rule for calculating sample size with four variables was used. Therefore, the sample size required for each group was 17.

The inclusion criteria were age $<18$ years, decreased consciousness, increased intracranial pressure, treatment with mannitol $20 \%$ in the PICU at Sanglah Hospital, and informed consent given by parents or guardians. The exclusion criterion was refusal of participation by parents or guardians. The study was approved by the ethical committee of Sanglah Hospital, with the protocol number 909.02.1.2016. The primary outcome was the patient's clinical outcome. Clinical characteristics such as age, sex, primary diagnosis, etiology, level of consciousness, nutritional status, outcome, and length of stay were also recorded.

Patients with brain edema received mannitol 20\%. The confirmed diagnosis of brain edema is based on one of the following criteria: (1) clinical brain edema including the classical syndrome of increased intracranial pressure (decreased consciousness, severe headache, projectile vomiting, blurred vision, papilledema, bradycardia, and hypertension), various and inconstant focal cerebral sign and lesions, and secondary complications such as cerebral herniation and (2) brain edema visible on a CT scan of the head. ${ }^{8}$

The timing of mannitol 20\% administration was calculated in hours from the time of admission to the hospital. The timing of mannitol administration since the onset of decreased consciousness was determined by asking the parent or guardian when the patient had lost consciousness. This variable of mannitol 20\% administration was dichotomized into more or less than 24 hours. Mohanty et $\mathrm{al}^{7}$ found that coma recovery time in surviving patients was shortened in those treated with mannitol, with a median coma recovery time of 24 hours with mannitol. 
The duration of decreased consciousness before hospitalization was defined as the period during which patients had been losing consciousness before their admission to the hospital. The level of consciousness was evaluated by the pediatric Glasgow coma scale (PGCS). The primary diagnosis is based on clinical and laboratory examination and decided by the consulting pediatrician in charge. The disease etiology can be divided into (1) traumatic brain injury such as intracerebral bleeding, subdural hemorrhage, epidural hemorrhage, and others and (2) non-traumatic brain injury such as encephalitis, meningitis, status epileptics, and others. ${ }^{1,8}$

Nutritional status was measured using the World Health Organization (WHO) chart and categorized on the basis of the Waterlow criteria. The clinical outcome was the patient's condition at discharge from the hospital, defined as normal (no sequelae), with sequelae, or death. The outcome of this study was sequelae, death, and normal based on the calculated sample size that is used for the mortality rate from Mohanty et al. ${ }^{7}$

Data were analyzed using Statistical Product and Service Solutions version 17. The chi-square test was used to test for an association between the timing of mannitol administration and the patient's clinical outcome. Results were considered significant at $\mathrm{p}<0.05$.

\section{RESULTS}

Between July 2016 and July 2017, 41 patients were included in the study (Figure $1)$. Among the 41 subjects who qualified for inclusion, the median age was 29 months (range: 1-127 months). In this study, the sample population was dominated by males with good nutritional status and non-traumatic cases with intracranial infection (Table 1). In this study, the dominant cause of intracranial infection was encephalitis, occurring in 27 cases (65\%). This study found that the risk of sequelae or death was 1.8 times higher in comatose vs non-comatose patients ( $p=0.018$ CI 95\% 1.119-3.047). Based on the timing of mannitol administration from the onset of decreased consciousness, the risk of sequelae or death for a patient who received mannitol after 24 hours was 2.1 times higher than that in a patient who received mannitol

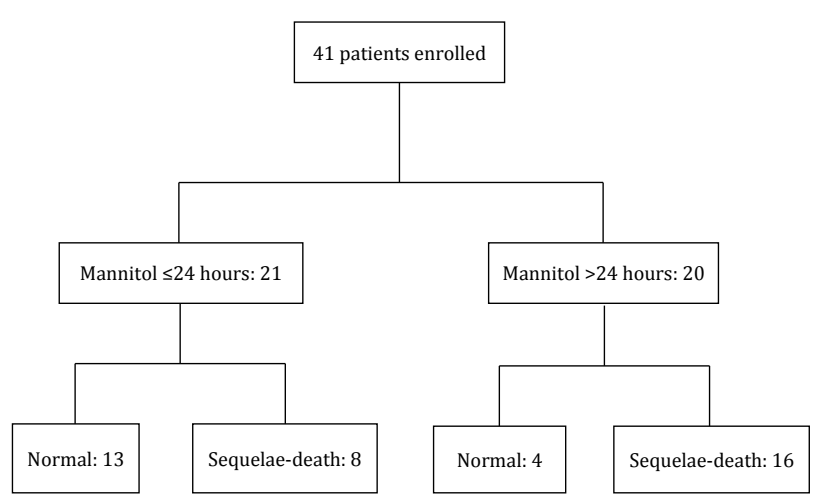

Figure 1. Enrollment and the outcome of the subjects in each group

Table 1. Subject characteristics

\begin{tabular}{|c|c|c|}
\hline Parameter & $\begin{array}{l}\text { Mannitol } \\
\text { administration } \\
\leq 24 \text { hours }\end{array}$ & $\begin{array}{c}\text { Mannitol } \\
\text { administration } \\
>24 \text { hours }\end{array}$ \\
\hline $\begin{array}{l}\text { Age, months, median } \\
\text { (range) }\end{array}$ & $50(3-127)$ & $30(1-79)$ \\
\hline Sex, male, n (\%) & $15(36)$ & 12 (29) \\
\hline $\begin{array}{l}\text { Duration of altered } \\
\text { consciousness before } \\
\text { hospitalization, } \\
\text { hours, median } \\
\text { (range) }\end{array}$ & $15(1-48)$ & $12(1-24)$ \\
\hline $\begin{array}{l}\text { PGCS on admission, } \\
\leq 3, \mathrm{n}(\%)\end{array}$ & 7 (17) & 7 (17) \\
\hline $\begin{array}{l}\text { Etiology, non- } \\
\text { traumatic, n (\%) }\end{array}$ & $19(46)$ & $18(43)$ \\
\hline $\begin{array}{l}\text { Primary diagnosis, } \\
\text { intracranial infection, } \\
\text { n (\%) }\end{array}$ & $14(47)$ & $16(53)$ \\
\hline \multicolumn{3}{|l|}{ Nutritional status } \\
\hline $\begin{array}{l}\text { Underweight, } \\
\mathrm{n}(\%)\end{array}$ & $4(9)$ & $5(12)$ \\
\hline Good, n (\%) & $14(34)$ & $13(31)$ \\
\hline Overweight, n (\%) & $2(6)$ & $2(6)$ \\
\hline Obesity, n (\%) & $1(2)$ & 0 \\
\hline $\begin{array}{l}\text { CT scan, brain } \\
\text { edema, } n(\%)\end{array}$ & $14(34)$ & $12(29)$ \\
\hline \multicolumn{3}{|l|}{ Outcome } \\
\hline Normal, n (\%) & $13(31)$ & $4(9)$ \\
\hline Sequelae, n (\%) & $5(12)$ & $10(24)$ \\
\hline Death, n (\%) & $3(7)$ & $6(17)$ \\
\hline $\begin{array}{l}\text { Length of stay, days, } \\
\text { median (range) }\end{array}$ & $9(3-21)$ & $15(2-30)$ \\
\hline
\end{tabular}

PGCS=pediatric Glasgow coma scale 
Table 2. Analysis of risk factors and clinical outcome

\begin{tabular}{|c|c|c|c|c|c|c|}
\hline Variable & $\begin{array}{c}\text { Sequelae/death } \\
n(\%)\end{array}$ & $\begin{array}{l}\text { Normal } \\
\text { n }(\%)\end{array}$ & $\mathrm{p}$ & $\mathrm{RR}$ & Adjusted RR & $\mathrm{p}$ \\
\hline \multicolumn{7}{|c|}{ Age (years) } \\
\hline$<5$ & $18(67)$ & $9(33)$ & \multirow{2}{*}{0.142} & \multirow{2}{*}{$1.556(0.803-3.013)$} & & \\
\hline$\geq 5$ & $6(43)$ & $8(57)$ & & & & \\
\hline \multicolumn{7}{|c|}{$\begin{array}{l}\text { Duration of altered } \\
\text { consciousness before } \\
\text { hospitalization (hours) }\end{array}$} \\
\hline$>12$ & $7(53.8)$ & $6(46.2)$ & \multirow{2}{*}{0.678} & \multirow{2}{*}{$0.887(0.494-1.592)$} & & \\
\hline$\leq 12$ & $17(60.7)$ & $11(39.3)$ & & & & \\
\hline \multicolumn{7}{|c|}{ PGCS on admission } \\
\hline$\leq 3$ & $13(81.3)$ & 3 (18.7) & \multirow{2}{*}{0.018} & \multirow{2}{*}{$1.8(1.119-3.047)$} & \multirow{2}{*}{$6.06(1.1-31.1)$} & \multirow{2}{*}{0.031} \\
\hline$>3$ & $11(44)$ & $14(56)$ & & & & \\
\hline \multicolumn{7}{|c|}{ Timing of mannitol (hours) } \\
\hline$\leq 24$ & $8(38.1)$ & $13(61.9)$ & \multirow{2}{*}{0.006} & \multirow{2}{*}{$2.1(1.167-3.779)$} & \multirow{2}{*}{$7.05(1.5-32.5)$} & \multirow{2}{*}{0.012} \\
\hline$>24$ & $16(80)$ & $4(20)$ & & & & \\
\hline
\end{tabular}

$\mathrm{RR}=$ relative risk; PGCS=pediatric Glasgow coma scale

before 24 hours ( $\mathrm{p}=0.006$ CI 95\% 1.167-3.779). Table 2 shows that two variables were associated with the patient's clinical outcome in multivariate analysis: PGCS score $\leq 3(\mathrm{p}=0.03)$ and the timing of mannitol administration $>24$ hours $(\mathrm{p}=0.01)$.

\section{DISCUSSION}

Brain edema and elevated ICP are common causes of morbidity and mortality. Brain edema is defined as an accumulation of fluid within the brain parenchyma, which increases brain volume. Brain edema is classified into three major categories: (1) cytotoxic; (2) interstitial; and (3) vasogenic. Cytotoxic edema results from a defect of cell membrane ATPdependent transport of sodium and calcium ions, leading to swelling of brain cells (neurons, glia, and endothelial cells). Cytotoxic edema affects predominantly the gray matter. Cytotoxic edema is most often seen in ischemic stroke and severe traumatic brain injury. Interstitial edema is commonly seen in hydrocephalus, when the outflow of cerebrospinal fluid is obstructed, and intraventricular pressure increases. Interstitial brain edema is also caused by meningitis due to obstruction of normal cerebrospinal fluid pathways, with a resulting increase in resistance to cerebrospinal fluid outflow. Vasogenic brain edema refers to the influx of fluid and solutes into the brain because of increased permeability of the capillary endothelial cells and is commonly seen in intracerebral hemorrhages, intoxication, tumors, and cerebral abscesses. Vasogenic brain edema primarily affects the white matter. ${ }^{2,3,6,8}$

Data suggest that mannitol reduces ICP by several mechanisms. Mannitol can (1) decrease the reabsorption of water and sodium across renal tubules, creating a diuretic effect; (2) reduce blood viscosity by reducing red cell rigidity; and (3) increase intravascular volume due to increased plasma osmolality, hence increasing cardiac output. When autoregulatory pathways remain intact, there is compensatory cerebral vasoconstriction. ${ }^{1-4,9,10}$

Based on the timing of mannitol administration from the onset of decreased consciousness, the risk of sequelae or death for a patient who received mannitol after 24 hours was 2.1 times higher vs a patient who received mannitol before 24 hours $(p=0.006$ CI 95\% 1.167-3.779). A study conducted in India determined that the effect of mannitol begins within 15 minutes of administration and continues for an additional 15 minutes, during which time it forms a gradient between the plasma and the cell. This effect will be stable for 
90 minutes to 6 hours or more, to a maximum of 1 day, depending on the clinical condition of the patient. ${ }^{9}$ A study in China by Mohanty et $\mathrm{al}^{7}$ found that coma recovery time in surviving patients was shortened to a median of 24 hours in those treated with mannitol. A prospective study in Brazil that included 44 patients with traumatic, acute, and severe diffuse brain swelling found that patients who received a high dose of mannitol $(\sim 1.4 \mathrm{~g} / \mathrm{kg})$ had significantly better outcomes than those who received the traditional dose $(\sim 0.7 \mathrm{~g} / \mathrm{kg})$. The best rate of favorable outcomes (good recovery or moderate disability) was $43.5 \%$, more than 4 times higher than that in patients who received conventionaldose mannitol $(\mathrm{p}<0.02){ }^{10}$

This study found that the risk of sequelae or death for patients in a coma was 1.8 times higher vs patients who were not in a coma ( $p=0.018$ CI 95\% 1.119-3.047). These results are concordant with a study from China conducted in 2013, which showed an increased risk of death for a head trauma patient with a Glasgow Coma Scale (GCS) $\leq 11$ with a relative risk (RR) value of 1.75 (CI 95\% 0.48-6.38). ${ }^{11}$ The duration of altered consciousness was not significantly associated with mortality, probably because these data were based on the recollections of the subjects' parents. Based on multivariate analysis, only 2 variables were associated with the clinical outcome. Subject age and duration of altered consciousness before hospitalization were not associated with the clinical outcome.

Mannitol can decrease brain volume by decreasing brain water content, reduce blood volume by vasoconstriction, reduce cerebral spinal fluid volume by decreasing water content, improve cerebral perfusion by decreasing viscosity or altering blood cell rheology, and have a protective effect against biochemical injury. ${ }^{10}$ Therefore, patients administered mannitol early had better outcomes in this study. Not all patients receive mannitol therapy; this therapy is only given in cases of intracranial infections and brain edema. Mannitol is administered within 24 hours if no contraindication is found.

Another study by Marcin et $\mathrm{al}^{12}$ who studied patient outcomes of brain edema due to diabetic ketoacidosis, found that mannitol was administered to $67 \%$ patients. Of the $67 \%$ of patients who received mannitol, $54 \%$ had normal outcomes without sequelae, $32 \%$ died, and the rest survived with sequelae. A study by Marcin et al showed similarities with this study, but all therapies, including mannitol administration, were administered within 24 hours. Marcin et al found that patient outcomes depended on hydration status upon admission to hospital and the value of blood urea nitrogen. ${ }^{12}$

The limitations of this study are its prospective cohort study design and small sample size; therefore, a larger study is needed to evaluate other contributing factors. The onset of a decreased level of consciousness was based on the parents' recollections, which depended on the ability of parents to recall the event, leading to a possible source of bias. Therefore, further research is needed to evaluate this variable.

In conclusion, early treatment ( $<24$ hours) and high PGCS are related to favorable outcomes in patients with brain edema in the PICU.

\section{Conflict of Interest}

The authors affirm no conflict of interest in this study.

\section{Acknowledgment}

The authors would like to thank Sanglah General Hospital Denpasar Bali and the patient's parents who have been willing to participate in this study.

\section{REFERENCES}

1. Gwer S, Gatakaa H, Mwai L, Idro R, Newton CR. The role of osmotic agents in children with acute encephalopathies: a systematic review. BMC Pediatr. 2010;10:23.

2. Oertel M, Kelly DF, Lee JH, McArthur DL, Glenn TC, Vespa $\mathrm{P}$, et al. Efficacy of hyperventilation, blood pressure elevation, and metabolic suppression therapy in controlling intracranial pressure after head injury. J Neurosurg. 2002;97(5):1045-53.

3. Nara I, Shiogai T, Hara M, Saito I. Comparative effects of hypothermia, barbiturate, and osmotherapy for cerebral oxygen metabolism, intracranial pressure, and cerebral perfusion pressure in patients with severe head injury. Acta Neurochir Suppl. 1998;71:22-6.

4. Tavakkoli F. Proceedings of the 18th expert committee on the selection and use of essential medicines; 2011 March 21-25; Baltimore, Maryland. USA.

5. Michinaga S, Koyama Y. Pathogenesis of brain edema and investigation into anti-edema drugs. Int J Mol Sci. 2015;16(5):9949-75. 
6. Shawkat H, Westwood MM, Mortimer A. Mannitol: a review of its clinical uses. Contin Educ Anaesth Crit Care Pain. 2012;12(2):82-5.

7. Mohanty S, Mishra SK, Patnaik R, Dutt AK, Pradhan S, Das $B$, et al. Brain swelling and mannitol therapy in adult cerebral malaria: a randomized trial. Clin Infect Dis. 2011;53(4):349-55.

8. Jha SK. Cerebral edema and its management. Med J Armed Forces India. 2003;59(4):326-31.

9. Wani AA, Ramzan AU, Nizami F, Malik NK, Kirmani AR, Bhatt AR, et al. Controversy in use of mannitol in head injury. Indian J Neurotrauma. 2008;5(1):11-3.
10. Cruz J, Minoja G, Okuchi K, Facco E. Successful use of the new high-dose mannitol treatment in patients with Glasgow Coma Scale scores of 3 and bilateral abnormal pupillary widening: a randomized trial. J Neurosurg. 2004;100(3):376-83.

11. Li J, Wang B. Hyperosmolar therapy for the intracranial pressure in neurological practice: mannitol versus hypertonic saline. IJAR. 2013;1:56-61.

12. Marcin JP, Glaser N, Barnett P, McCaslin I, Nelson D, Trainor J, et al. Factors associated with adverse outcomes in children with diabetic ketoacidosis-related cerebral edema. J Pediatr. 2002;141(6):793-7. 